\title{
Developing national institutional capacity for evidence-informed policy-making for health
}

Citation: Developing national institutional capacity for evidence-informed policy-making for health. East Mediterr Health J. 2021;27(3):314-315 https:// doi.org/10.26719/2021.27.3.314

Copyright @ World Health Organization (WHO) 2021. Open Access. Some rights reserved. This work is available under the CC BY-NC-SA 3.0 IGO license (https://creativecommons.org/licenses/by-nc-sa/3.o/igo).

\section{Introduction}

As highlighted in Regional Committee technical paper EM/RC66/6 (1), health policies need to be based on sound evidence to ensure that they are appropriate, effective and cost-effective. Evidence-informed policy-making is therefore essential to achieve the Sustainable Development Goals and universal health coverage, and its importance is emphasized repeatedly in WHO's current global strategy, the Thirteenth General Programme of Work 2019-2023 (GPW 13) (2).

Over the years, WHO has taken important steps to strengthen evidence-informed policy-making in the countries of the Region. In a landmark resolution (EM/ RC66/R.5) in 2019, a framework for "improving national institutional capacity for use of evidence in health policy making in the Eastern Mediterranean Region" (3) was endorsed and as a key request, EM/RC66/R.5 envisaged the development of an action plan for the implementation of the framework. In addition, Regional Office (WHO/ EMRO) mandates to establish the regional network of institutions to enhance the use of evidence for policy development at national levels. The regional action plan intends to support the Member States to develop national mechanism to support and enhance evidence-informed policy-making and the network will play an important role in strengthening regional and country capacity to improve the availability, quality and use of evidence for decision-making and institutionalizing the use of evidence at national level.

The virtual Intercountry Consultative Meeting was held by WHO/EMRO on 16 November 2020 (4).

The objectives of the meeting were to:

- discuss the draft regional action plan for the implementation of the framework for action to improve national institutional capacity for the use of evidence in health policy-making in the Eastern Mediterranean Region (2020-2024);

- seek the support of the countries in the Region to finalize the formal arrangements for establishing the Regional Network of Institutions for Evidence and Data to Policy (NEDtP).

The meeting was attended by senior policy-makers from ministries of health, managers and key researchers from national institutions, supporting institutions for NEDtP, including the Alliance for Health Policy and System Research, McMaster University and regional and global well-known institutions, as well as directors and senior
WHO staff from the Regional Office for the Eastern Mediterranean Region, Cairo, Egypt, and WHO headquarters, Geneva, Switzerland.

\section{Summary of discussions}

The morning session began with the topic of the regional action plan. First, a brief presentation on rationale and components of the action plan were presented, and then the recommendations of countries were discussed. In the evening session, first presentations were made by directors and senior WHO staff about the role of these initiatives in their programmes and then the issue of establishing NEDtP were discussed, stating its mission and objectives as well as the role of the Regional Office and the Member Institutions.

It was discussed that now is a strategic time in the region to establish national mechanisms in which systematic and regular use of evidence for policy making for health is followed and for this WHO/EMRO and its country offices should enhance their technical capacity, keep it updated to support and become the ambassadors for the use of evidence in health policy-making. It was emphasized the countries should also take into account internal programmes and technical streams to promote a systematic unified approach of evidence-informed policy-making at the national levels.

\section{Recommendations}

\section{To WHO}

- Enhancing WHO/EMRO capacity and output in support of evidence-informed policy-making in Eastern Mediterranean Region countries through supporting;

- development and adaptation of evidence based guidelines for high priority topics;

- evidence-informed policy-making processes and development of policy briefs and implementation guides;

- rapid response processes in adaptation or development of evidence-informed policy recommendations in emergency settings;

- supporting countries in improving national institutional capacity for evidence-informed policy-making through;

- providing technical support to countries to strengthen national institutional capacity development;

- strengthening communication tools and advocacy to enhance evidence-informed policy-making; 
- establishing a Regional Network and Support Structure through establishing:

- a Regional Network of Institutions for Evidence and Data to Policy (NEDtP);

- a NEDtP secretariat.

\section{To Member States}

- Enhancing demand and advocacy for evidence-informed-policy making;

- enhancing decision making structures and processes for use of evidence through;

- enhancing technical capacity of Ministry of Health staff in critical appraisal of knowledge products and evidence synthesis reports'

- establishing dedicated evidence to policy team(s) within the Ministry of Health including all key expertise areas;
- enhancing national policy-making committees decision making processes;

- establishing special programs (such as national Health Technology Assessment and guideline adaptation/development programmes) for evidence-informed decision making;

- establishing mechanisms to regulate and manage conflicts of interests and enhance transparency in policy-making;

- establishing support structures and affiliations.

- enhancing resources for evidence-informed policymaking through:

- enhancing access to sources of knowledge and research evidence for health;

- foreseeing adequate and sustainable financing to support evidence-informed policy-making;

- enhancing national academic capacity for evidence-informed policy-making.

\section{References}

1. WHO Regional Committee for the Eastern Mediterranean resolution EM/RC66/ R.5 on developing national institutional capacity for evidence-informed policy-making for health, Cairo: WHO Regional Office for the Eastern Mediterranean, 2019 (https:// applications.emro.who.int/docs/RC66-R5-eng.pdf?ua=1).

2. World Health Organization Regional Office for the Eastern Mediterranean (WHO/EMRO). Technical paper EM/RC66/6, Developing National Institutional Capacity for Evidence Informed Policy Making for Health. Cairo: WHO/EMRO; 2019 (https://applications.emro.who.int/docs/RC_Technical_Papers_2019_6_en.pdf?ua=1).

3. Framework for improving national institutional capacity for use of evidence in health policy-making in the Eastern Mediterranean Region; appended to RC technical paper EM/RC66/6. Cairo: WHO/EMRO; 2019 (https://applications.emro.who.int/docs/ EMSIDooiE.pdf).

4. World Health Organization Regional Office for the Eastern Mediterranean (WHO/EMRO). Summary report on the Intercountry consultative meeting for the Network of Institutions for Evidence and Data to Policy (NEDtP) and finalizing the regional action plan for evidence-informed policy-making. Cairo: WHO/EMRO: 2020 (https://applications. emro.who.int/docs/ WHOEMEDPoolE-eng.pdf?ua=1). 